\title{
Economic Empowerment of the People Through Farming Capital Assistance without Service Fees Study on Baitul Mal, Aceh Province
}

\author{
Achmad Muchaddam $^{1}$., T. Ade Surya ${ }^{2}$, Achmad Wirabrata $^{3}$, Mohammad Teja $^{4}$, \\ Teddy Prasetiawan ${ }^{5}$, Simela Victor Muhamad ${ }^{6}$ \\ achmad.fahham@gmail.com ${ }^{1}$,soerya_roman@yahoo.com ${ }^{2}$,awirabrata@yahoo.com ${ }^{3}$, \\ moht3j4@gmail.com,teddy.prasetiawan@gmail.com ${ }^{5}$,simelavictor@ayhoo.com ${ }^{6}$
}

Sekretariat Jenderal dan Badan Keahlian DPR RI, Jakarta1,2,3,4,5,6

\begin{abstract}
Baitul Mal Aceh is an institution that manages zakat in Aceh Province. This institution is given the function to collect and distribute zakat, collect data on muzakki and mustahik, research on religious assets, use of religious assets, increase the quality of assets, religion, and empowerment of religious assets in accordance with Sharia law. Islam. One of the Baitul Aceh programs is to empower the economic community of the people through the assistance of venture capital without compensation and profit sharing. This study was conducted to determine whether the community economic empowerment program carried out by Baitul Mal Aceh can increase economic income mustahik? Does the economic empowerment of the people have an impact on poverty alleviation? This study was conducted with a qualitative approach, the data collected through literature and field studies. Field studies were conducted by conducting FGDs and in-depth interviews with informants determined purposively. The data that has been collected are analyzed by means of presentation, presentation, and conclusion drawing. The results of this study show that the economic empowerment of the people carried out by Baitul Mal Aceh through qardhul hasan business capital assistance was able to increase the economic income of mustahik who received venture capital assistance, but had not yet been able to have an impact on the economic empowerment of the community at large. namely Baitul Mal Gampong which specifically implements the program at the village level, not all of them are able to implement the program properly. Baitul Mal Aceh needs to improve monitoring and evaluation of the qardhul hasan business capital assistance program, besides Baitul Mal Aceh also needs to foster and increase resource capacity human resources, both the Baitul Mal Aceh HR itself, and the Baitul Mal Gampong HR. Without good monitoring, program evaluation and human resource development efforts, the economic empowerment program is difficult to increase its impact on society at large.
\end{abstract}

Keywords:capital assistance, empowerment, economy, qardhul hasan, mustahik, muzakki, and zakat 


\section{Pendahuluan}

Aceh merupakan provinsi dengan angka kemiskinan tertinggi di Pulau Sumatera dan berada pada peringkat enam tertinggidi Indonesia.[1] Berdasarkan data Badan Pusat Statistik (BPS), persentase penduduk miskin di Aceh per September 2018 yaitu sebesar 15,68 persen atau sebanyak 831,5 ribu jiwa dari sekitar 5,2 juta jiwa penduduk di Aceh, jauh di atas ratarata angka kemiskinan nasional yang hanya sebesar 9,66 persen.[2] Tingginya angka kemiskinan di Aceh mengejutkan banyak pihak, karena hingga saat ini Aceh merupakan salah satu dari dua provinsi yang mendapatkan dana Otonomi Khusus (Otsus), setiap tahun Aceh menerima dana Otsus sekitar 7-8 triliun, dan telah berlangsung sejak tahun 2008. Di sisi lain, pagu Anggaran Pendapatan Belanja Aceh (APBA) juga cukup tinggi, yakni sebesar 15-17 triliun rupiah Anggaran Pendapatan Belanja Kabupaten/Kota (APBK) juga rata-rata di atas 1 triliun rupiah.[3] Besarnya jumlah dana dan anggaran ini seharusnya dapat menekan angka kemiskinan di Aceh. Namun hal itu tidak terjadi.Pertanyaannyakemudian mengapa angka kemiskinan di Aceh hingga saat ini masih cukup tinggi. Ada yang melihat upayaupayapenanggulangan kemiskinan yang dilakukan Pemerintah Aceh hingga saat ini belum membuahkan hasil yang signifikan.[4] Meskipun demikian, tren angka kemiskinan di Aceh sebenarnya menurun dalam 5 tahun terakhir, tetapi penurunannya sangat lambat, seperti yang ditunjukkan pada Tabel berikut.

Tabel 1.Jumlah Penduduk Miskin Aceh, serta Perbandingan Persentase Penduduk Miskin Aceh dan Nasional Tahun 2014 - 2018

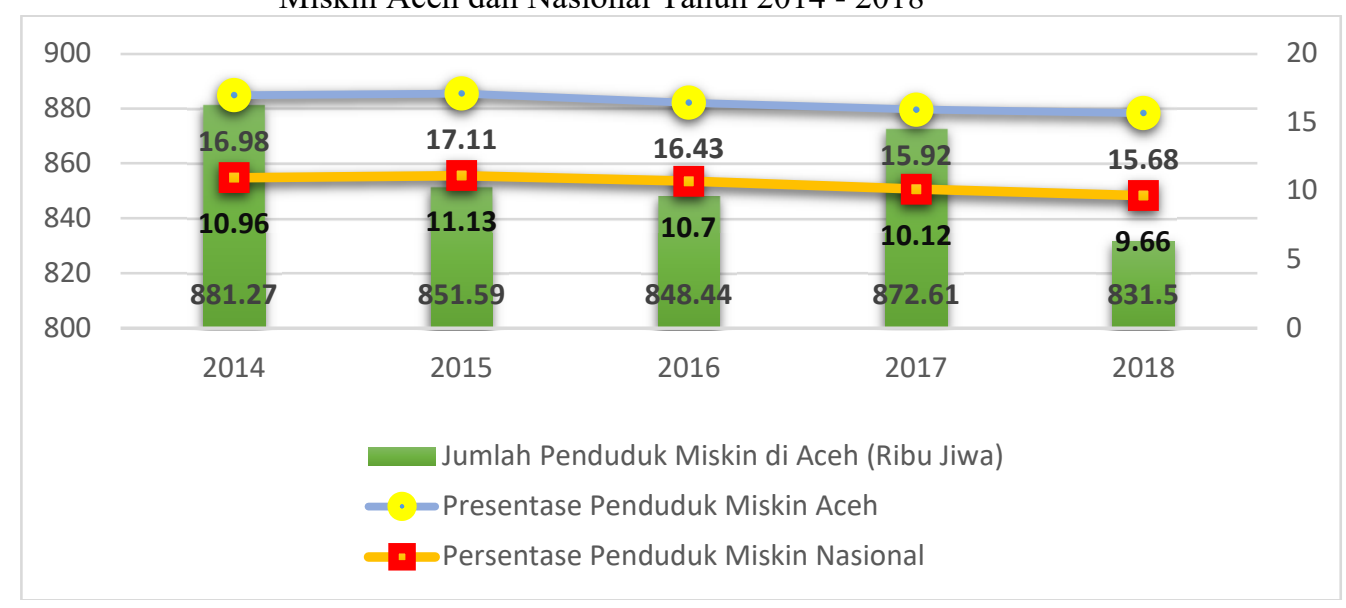

Sumber: Diolah dari berbagai sumber.

Jika dibandingkan dengan provinsi lain di Indonesia, derajat otonomi fiskal cukup kecil. Hal itu menjadi salah satu penyebabmengapa Aceh sulit menekan angka kemiskinannya. Selain itu, danadan anggaran yang dimiliki Pemerintah Aceh baik dari Pendapatan Asli daerah (PAD) maupun dana transfer tidak cukup fleksibel untuk dialokasikan dalam programprogram penanggulangan kemiskinan. Dana Otsus misalnya penggunaannya sudah terikat pada polapembagian, sekian persen yang harus dialokasikan ke kabupaten dan provinsi, 20 persen harus dialokasikan untuk pendidikan dan 10 persen harus dialokasikan untuk kesehatan.Padahal jika dikaji lebih dalam, pada tingkat provinsi misalnya, tidak memerlukan 
alokasi 20 persen untuk pendidikan karena yang lebih membutuhkan adalah kabupaten/kota sebagai pengelola pendidikan dasar sampai pada tingkat sekolah menengah pertama (SMP).Selain itu, program penanggulangan kemiskinan yang disusun oleh Pemerintah Aceh tidak efektif karena tidak didesain dengan baik, tidak sistematis, tidak tepat sasaran, dan tidak tepat cara penyaluran.[5]

Secara umum, kemiskinan di Provinsi Aceh disebabkan oleh beberapa factor;pertama, tingginya beban pengeluaran penduduk miskin.Meskipun sudah ada program-program seperti jaminan kesehatan (jamkes), beasiswa, dan sebagainya, tetapi karena ketidaktepatan desain dan implementasi menyebabkan masih adanya masyarakat miskin yang tidak mendapatkan akses terhadap perlindungan sosial tersebut;kedua, rendahnya pendapatan masyarakat sehingga sulit untuk memenuhi standar hidup yang layak. Sementara lapangan pekerjaan belum tersedia dan iklim usaha serta investasi cukup buruk;ketiga, rendahnya tingkat pendidikan dan keterampilan di kalangan penduduk miskin yang menyebabkan kualitas sumber daya manusia (SDM) rendah;keempat,tingginya biaya transaksi ekonomi karena konektivitas antarwilayah belum cukup baik walaupun pembangunan infrastrukur sudah banyak dilakukan; dankelima, tingginya harga-harga bahan kebutuhan pokok.[6]

Berangkat dari persoalan-persoalan tersebut, Pemerintah Aceh mempunyai lima strategi utama penanggulangan kemiskinan, yaitu: (1) mengurangi beban penduduk miskin dengan program perlindungan sosial yang bersinergi antara skema pemerintah Aceh dengan skema pusat melalui redesain program; (2) meningkatkan pendapatan penduduk miskin dengan menumbuhkan pusat-pusat ekonomi baru di daerah-daerah yang padat penduduk miskin; (3) meningkatkan kualitas SDM termasuk pendidikan karakter yang berbasis pada keislaman juga adat-istiadat dan budaya Aceh; (4) Pembangunan infrastruktur untuk konektivitas terus ditingkatkan agar dapat mengendalikan tingginya biaya-biaya transaksi yang harus dikeluarkan oleh masyarakat dan pelaku usaha; (5) Pengendalian harga-harga kebutuhan pokok dengan mewujudkan ketahanan pangan.[7]

Pemerintah Aceh memang perlu mencari formula yang tepat dalam menanggulangi kemiskinan di daerahnya. Di samping itu, hal lain yang juga perlu menjadi perhatian pemerintah Aceh, adalah soal ketersediaan data angka kemiskinan yang valid. Pemerintah dan BPS perlu memvalidasi data kemiskinan terlebih dahulu, karena ada beberapa kepala daerah di Aceh yang turun ke lapangan kemudian melakukan validasi data kemiskinan dengan metode by name by address. Hasilnya menunjukkan bahwa banyak pendudukyang tidak miskin tetapidalam data BPS penduduk tersebut dikategorikan sebagai penduduk miskin.[8] Permasalahannya, beberapa indikator yang digunakan oleh BPS dalam menentukan data angka kemiskinan di Aceh kurang tepat, seperti indikator kepemilikan tanah sesuai sertifikat dan makanan yang dikonsumsi masyarakat sehari-hari. Sebagian besar masyarakat Aceh yang berprofesi sebagai petani memang tidak menguasai tanah sesuai dengan sertifikat, karena mereka menggarap hutan sosial yang bekerjasama dengan Taman Nasional Gunung Leuser (TNGL) dan pemangku hutan lainnya. Meski demikian, banyak petani yang sukses.Indiktor lainnya yang digunakan untuk mengukur kemiskinan di Aceh adalah makanan.Masyarakat Aceh tidak terlalu sering makan daging dan minum susu. Jikaini menjadi salah satu indikator penilaian tingkat kemiskinan, maka banyak orang Aceh yang miskinkarena tradisi di Aceh, makan daging biasanya dilakukan pada hari meugang dan hari raya.[9]

Dari segi harta, sebenarnya masyarakat Aceh tidak miskin, mereka miskin dari segi perilaku.Contohnya, ada masyarakat yang mempunyai kerbau sampai 30 ekor, namun dia tidak peduli dengan rumahnya.Rumahnya berlantai tanah tetapi dia punya kerbau atau hewan peliharaan yang jika dihitung dengan uang maka mereka tidak dapat dikategorikan sebagai orang miskin. Jika data angka kemiskinan yang dikeluarkan benar-benar valid maka program 
penanggulangan kemiskinan juga bisa tepat sasaran.[10] Selain data angka kemiskinan tidak valid, selama ini penggunaan anggaran oleh pemerintah juga tidak fokus. Anggaran digunakan hanya untuk dihabiskan, tidak terintegrasi pada sektor-sektor penting seperti pemberdayaan ekonomi, penguatan pasar, dan pengentasan kemiskinan dengan memperbaiki infrastruktur seperti jalan tembus ke sentra produksi.[11]

Terlepas dari berbagai permasalahan di atas, studiini berusaha mengkaji satu sisi upaya penanganan kemiskinan di Aceh yang dilakukan oleh Baitul Mal Aceh, sebuah lembaga otonom yang diberi wewenang untuk mengumpulkan dan mendistribusikan zakat, infak, sedekah, dan harta agama lainnya di Provinsi Aceh. Dana zakat yang berhasil dikumpulkan oleh lembaga ini didistribusikan kepada mustahik dalam dua pola, pertama, pola konsumtif dan kedua, pola produktif.Salah satu bentuk distribusi zakat produktif yang dilakukan oleh Baitul Mal Mal Aceh adalah pemberdayaan ekonomi umat melalui bantuan modal usaha dengan perjajian tanpa imbal jasa (qardhul hasan).Dana zakat dan infak yang berhasil dikumpulkan dari tahun ke tahun cukup besar. Pada tahun 2013,dana zakat yang kumpulkan sebesar Rp11.285.431.670 (Sebelas Miliar Tiga Ratus Delapan Puluh Lima Juta Empat Ratus Tiga Puluh Satu Ribu Enam Ratus Tujuh Puluh Rupiah). Sementara dana infak yang terkumpul sebesar Rp26.006.282,834 (Dua Puluh Enam Miliar Enam Juta Rupiah Dua Ratus Delapan Puluh Dua Ribu Delapan Ratus Tiga Puluh Empat Rupiah), dan terus mengalami peningkatan sebagaimana terlihat pada tabel berikut:[12]

Tabel 2. Penerimaan Zakat, Infak, dan Sedekah Baitul Mal Aceh Periode 2013 s.d. 2017

\begin{tabular}{|l|l|l|}
\hline Tahun & Zakat (Rp) & Infak dan Sekekah (Rp) \\
\hline 2013 & 11.385 .431 .670 & 26.006 .282 .834 \\
\hline 2014 & 21.600 .956 .235 & 25.176 .003 .088 \\
\hline 2015 & 21.264 .480 .978 & 27.312 .498 .282 \\
\hline 2016 & 22.456 .881 .595 & 27.970 .836 .358 \\
\hline 2017 & 23.602 .012 .262 & 53.427 .890 .290 \\
\hline
\end{tabular}

Ada beberapa studi yang sudah dilakukan untuk menelaah program pemberdayaan ekonomi umat yang dilaksanakan Baitul Mal Aceh, di antaranya Djawas,[13] Saputra, [14] Nasrullah,[15] Yusuf [16], Nur dan Nurlaela [17],Rayyan Firdaus dan Mukhlish M. Nur, [18] Ristyana Tri Hastuti \& Ahmad Redi [19] Namun studi-studi tersebut tidak menelaah dampak program pemberdayaan ekonomi umat tersebut terhadap masyarakat miskin di Aceh.Program pemberdayaan ekonomi umat yang dilakukan Baitul Aceh diharapkan dapat meningkatkan penghasilan masyarakat miskin.Di samping itu, program tersebut juga merupakan salah satu bentuk pemberian kemudahan akses modal bagi pelaku usaha kecil yang selama ini kesulitan memperoleh kredit atau pinjaman dari lembaga keuangan, baik yang berbentuk bank maupun nonbank.Studi ini dilakukan untuk mengetahui apakah program pemberdayaan ekonomi umat yang dilakukan oleh Baitul Mal Aceh dapat meningkatkan pendapatan ekonomi mustahik dan apakah pemberdayaan ekonomi umat berdampak pada pengentasan kemiskinan. 


\section{Bantuan Modal Usaha Qardhul Hasan}

Pemberdayaan ekonomi masyarakat, dapat dilakukan dengan beberapa strategi, ada strategi makro, messo, dan mikro.Strategi makro dilaksanakan dengan membuat berbagai rumusan kebijakan, aksi sosial, dan perencanaan sosial untuk menjangkau sasaran perubahan masyarakat dalam skala yang lebih luas.Sementara strategi messo, dilaksanakan terhadap sekelompok masyarakat sebagai media intervensi. Sedangkan strategi mikro dilakukanterhadapindividu[20] Dari tiga strategi itu, Baitul Mal Aceh, memilih strategi pemberdayaan ekonomi mikro dan messo. Pemberdayaan ekonomi umat padaBaitul Mal Acehdilaksanakan dalam bentuk pemberian modal usaha bergulir kepada pelaku usaha ekonomi mikro.Karena bergulir, penerima bantuan modal usaha memiliki kewajiban untuk mengembalikan bantuan.Tetapi akad pemberian modal usaha itu menggunakan qardhul hasan.Dalam kajian ekonomi syariah, qardhul hasan dimaknai sebagai transaksi pinjam meminjam tanpa syarat tambahan pada saat pinjaman.Qardh, dimaknai sebagai perjanjian pinjaman. Dalam perjanjian pinjaman ini, pemberi pinjaman memiliki kewajiban mengembalikan pinjaman tersebut pada waktu yang telah ditentukan dengan jumlah yang sama ketika pinjaman itu diberikan.[21]

Mengapa Baitul Mal Aceh menggunakan qardhul hasan sebagai model bantuan modal usaha untuk pemberdayaan masyarakat miskin? Mengapa tidak menggunakan model transaksi lain seperti mudarabah. Pilihan terhadap qardhul hasan, bukan tanpa alasan.Pertama, dana yang digunakan untuk memberi bantuan berasal dari harta zakat. Dana ini seharusnya langsung diberikan kepada mustahik, tetapi di Baitul Mal Aceh, dana zakat tidak saja distribusikan secara konsumtif, tetapi juga secara produktif. Penggunaan harta zakat secara produktif dibenarkan, termasuk untuk bantuan modal usaha dalam bentuk qardhul hasan.Hal itu sesuai dengan Fatwa MUI tentang Penggunaan Dana Zakat untuk Istitsmar (Investasi) [22] dan pendapat Tarjih tentang Memanfaatkan Harta Zakat untuk Modal Usaha.[23] Kedua, pilihan terhadap pemberian bantuan modal usaha yang menggunakan qardhul hasan itu tidak membebani mustahik dengan jasa pengembalian, ini berbeda jika bantuan diberikan dalam bentuk mudharabah yang mewajibkan adanya bagi hasil antara pemberi bantuan modal usaha dengan mustahik.[24] ketiga, pilihan terhadap qardhul hasan merupakan bentuk komitmen Baitul Mal Aceh dalam pemberdayaanumat.Program ini diharapkan mampumeningkatkan kesejahteraan dan kemandirianmustahik secara ekonomi. Target jangka panjangpemberian modal usaha ini adalah mentransformasi mustahik menjadi muzakki dan mampu berkontribusi pada pengurangan angka kemiskinan.[25]

Untuk mengelola harta zakat sebagai bantuan modal usaha, Baitul Mal Aceh membentuk unit ZIS Produktif.Unit ini dibentuk melalui Keputusan Kepala Baitul Mal AcehNomor 821/22/SK/IV/2016 dan kedudukannyaberada di bawah koordinasi Bidang Pendistribusiandan Pendayagunaan.Pada awalnya, ZIS produktif yang ada pada Baitul Mal Aceh dikelola UPZP (UnitPengelola Zakat Produktif).Unit ini dibentuk sejak 2006 dan berakhir pada 2011.Sejak 2011-2014, UPZP berubah menjadi LKMS (Lembaga KeuanganMikro Syariah).Mulai awal tahun 2015 sampai sekarang LKMS kembali berganti nama menjadi UnitZIS Produktif.[26]

Sasaranprogram pemberdayaan ekonomi umat melalui bantuan modal usaha qardhul hasan iniadalah para pelaku usaha mikro di BandaAceh dan sebagian Aceh Besar baik mustahik baru maupunmustahik binaan Unit ZIS Produktif Baitul Mal Aceh. Agar dapat terlaksana dengan baik, Pengelola Unit ZIS Produktif menetapkan syaratmendapatkan modal usaha dana bergulir, sebagai berikut:pertama, tercatat dalam kategori masyarakat miskin atauusaha kecil, dibuktikan verifikasi di lapangan, kedua, mempunyai usaha yang telah berjalan lebih dari 1tahun, dibuktikan dengan Surat KeteranganUsaha dari keuchik, 
ketiga,mustahik Binaan Baitul Mal Aceh yang tidakmemiliki tunggakan pembiayaan, keempat,berdomisili di Kota Banda Aceh dan sebagianAceh Besar, dibuktikan dengan Kartu TandaPenduduk (KTP) dan Kartu Keluarga(KK), kelima, memiliki jaminan pendukung, jika pemohonberstatus rumah sewa dan permohonanpembiayaan diatas Rp6.000.000, keenam, tidak memiliki catatan tunggakan/macet dilembaga keuangan lainnya atau pinjaman/utang pada pihak lainnya.[27]

Pada tahun 2017, Baitul Mal Aceh telah memberikan bantuan modal usaha kepada 491 pelaku usaha mikroyang tersebar di wilayah Banda Aceh dan Aceh Besar. Baitul Maltelah menggulirkan pinjaman modal usaha tanpa bungaini dengan total pembiayaan sebesar $\mathrm{Rp}$ 3.237.500.000,00 (Tiga Miliar Dua RatusTiga PuluhTujuh Juta Lima Ratus Ribu Rupiah).Program bantuan modal usaha dengan model qardhul hasan ini, pada umumnya mampu meningkatkan pendapatan mustahik. Ibu Ani misalnya, seorang pedagang kue yang berjuang menghidupi anak-anaknya setelah suaminya wafat akibat tsunami 2005, setelah memperoleh bantuan modal tanpa imbal jasa ini Ibu Ani mampu mengembangkan usaha kuenya, dari pendapatan sekitar 100.000 perhari kini sudah mencapai 300.000-500.000 perhari, dari usaha kue tersebut, ia mampu membiayai pendidikan anak-anak, bahkan kini sudah ada yang kuliah di perguruan tinggi. [20], selain membantu mustahik meningkatkan pendapatannya, program ini juga membantu mustahik yang memiliki usaha terhindar dari renternir, yang datang untuk meminjamkan sejumlah dana dengan bunga yang cukup tinggi, bahkan bunganya melebihi bunga pinjaman bank atau lembaga keuangan nonbank lainnya.

Meskipun program ini dipandang mampu meningkatkan pendapatan mustahik dan menghindarkan mereka dari praktik rentenir yang menetapkan bunga pinjaman yang tinggi, akan tetapi dalam pelaksanaannya ada beberapa kendala yang dihadapinya, yakni pertama, masih banyak masyarakat miskin yang belum tersentuh program pemberdayaan ini, sehingga dampaknya belum signifikan dapat dirasakan oleh masyarakat. Kedua, masih ada mustahik yang menunggak angsuran pengembalian dana. Ketiga, masih ada modal usaha yang belum tersalurkan kepada mustahik, terutama modal usahayang diberikan kepada Baitul Mal Gampong (BMG).Hal ini terjadi karena Tetapi BMGtarnyata tidak mampu menyalurkan dana tersebut.Sebenarnya BMG telah diberi kewenangan untuk membentuk kelompok usaha dan mengembangkan usaha tertentu, tapi peran itu belum mampu dijalankan oleh BMG.Keempat, keterbatasan sumber daya manusia yang dimiliki oleh Baitul Mal Aceh dalam pelaksanaan program pemberdayaan ekonomi umat.Hal ini tampak pada kasus yang terjadi pada sebagian Baitul Mal Gampong yang diberi amanat untuk menyalukan bantuan modal usaha.Untuk melaksanakan proram ini di tengah-tengah masyarakat, Baitul Mal Aceh memberikan program ini kepada Baitul Mal Gampong di tingkat desa, tetapi tidak semua Baitul Mal Gampong mengetahui dan memahami tujuan program ini.

\section{Kesimpulan}

Pemberdayaan ekonomi umat melalui bantuan modal usaha dengan akad qardhul hasan yang dilaksanakan oleh Baitul Mal Aceh memberikan dampak pada peningkatan pendapatan pelaku usaha mikro (mustahik), membantu pelaku usaha untuk memperoleh akses modal dan menghindari rentenir.Program ini perlu dukungan perencanaan, pembinaan, pemantauan dan evaluasi berkelanjutan sehingga dapat menjadi program yang memberikan dampak luas pada peningkatan pendapatan masyarakat.Program ini juga perlu didukung dengan sumber daya manusia yang kompeten agar dapat menjangkau mustahik yang lebih banyak, gampong yang 
lebih luas dengan memperhatikan letak geografis di mana masyarakat miskin berada.Baitul Mal Aceh perlu melakukan pendampingan dan pembinaan kepada Baitul Mal Gampong, dengan cara melatih sumber daya manusia yang tersedia pada Baitul Mal Gampong agar mereka mampu memahami tujuan program, menjalankan tugas dan fungsinya, serta mampu melakukan identifikasi sektor usaha mikro yang dapat berkembang agar bantuan modal usaha yang diberikan dapat bergulir dengan baik dan terhindar dari mustahik yang menunggak pengembalian bantuan modal usaha tersebut. BMG perlu didorong agar mampu mendayagunakan dana bantuan modal usaha yang telah diberikan kepada mereka dengan membentuk kelompok usaha yang kreatif.

\section{References}

[1]Muhammad Taufiqurrahman, Agus Setyadi, Aceh Provinsi Termiskin di Sumatera, dalam https://news.detik.com/berita/d-4385686/aceh-provinsi-termiskin-di-sumatera, diakses 8 Juli 2019

[2]Badan Pusat Statistik. (2019). "Indikator Strategis". http://aceh.bps.go.id/quickMap.html, diakses 22 Juli 2019.

[3]Anonim, Dana Otsus Rp56 Triliun Lebih, Kemiskinan di Aceh Justru Meningkatdalam https://news.okezone.com/read/2018/07/17/340/1923627/dana-otsus-rp56-triliun-lebihkemiskinan-di-aceh-justru-meningkat, diakses 8 Juli 2019

[4]Hasil Focus Group Discussion (FGD) Tim Peneliti Pusat Penelitian Badan Keahlian DPR RI dengan LSM Flower Aceh, tanggal 10 Juli 2019.

[5]Bakri (ed.) Mengapa Aceh Tetap Miskin?dalamhttps://aceh.tribunnews.com/2019/04/15/mengapa-aceh-tetap-miskin. $\quad 15$ April 2019.

[6]Hasil Wawancara Penelitian Lintas Bidang tentang "Human Security dalam Kebijakan Nasional Indonesia" dengsn Badan Perencanaan Pembangunan Daerah Provinsi Aceh, Banda Aceh, 10 Juli 2019.

[7]Hasil Wawancara Penelitian Lintas Bidang tentang "Human Security dalam Kebijakan Nasional Indonesia" dengan Badan Perencanaan Pembangunan Daerah Provinsi Aceh, Banda Aceh, 10 Juli 2019.

[8] Wawancara dengan Baitul Mal Aceh, Tanggal 9 Juli 2019

[9] Bakri (ed.) Mengapa Aceh Tetap Miskin?dalamhttps://aceh.tribunnews.com/2019/04/15/mengapa-aceh-tetap-miskin. 15 April 2019.

[10] Wawancara dengan Baitul Mal Aceh, Tanggal 9 Juli 2019

[11]Bakri (ed.) Mengapa Aceh Tetap Miskin? Dalam aceh.tribunnews.com, 15 April 2019

[12]Baitul Mal Aceh, Laporan Tahun Baitul Mal Aceh 2017, hlm. 15.

[13]Mursyid Djawas, Implementasi Pengelolaan Zakat di Aceh, dalam Mazahib,Vol XV, No. 1, Juni 2016, Pp. 90-103 DOI: http://dx.doi.org/10.21093/mj.v15i1.613

[14]Hendra Saputra, Pengelolaan Zakat Produktif: Suatu Analisis Terhadap Mekanisme Pengelolaan Zakat di Baitul Mal Aceh, (Banda Aceh: Pasca Sarjana, IAIN AR-Raniry, 2009), hlm. 56.

[15] Nasrullah, Regulasi Zakat Dan Penerapan Zakat Produktif sebagai Penunjang Pemberdayaan Masyarakat: Studi Kasus pada Baitul Mal Kabupaten Aceh Utara, dalam INFERENSI, Jurnal Penelitian Sosial Keagamaan, Vol. 9, No. 1, Juni 2015, hlm., 1-24. 
[16]Muhammad Yasir Yusuf, Model Pelaksanaan CRS Bank Syariah: Kajian Empiris Pembiayaan Mikro Baitul Mal Aceh. Dalam La Raiba Vol. IV No. 2 Desember 2010, hlm. 197-215.

[17]Mukhlish Muhammad Nur dan Nurlela, Model Pemberdayaan Ekonomi Berbasis Zakat Produktif dalam Meningkatkan Kesejahteraan Masyarakat di Provinsi Aceh.Paper Seminar Nasional Fakultas Ekonomi dan Bisnis Universitas Lhokseumawe.

[18]Rayyan Firdaus dan Mukhlish M. Nur, Model Pemberdayaan Ekonomi Berbasis Zakat Produktif dalam meningkatkan Pendapatan Masyarakat di Provinsi Aceh dalam Rahimah Embong, Mohamad Zaidin Mat (ed). Proceeding of International Conference of Empowering Islamic Civilization, Research Institute for IslamicProduct and Malay Civilization (INSPIRE) Universiti Sultan Zainal Abidin (UniSZA), 2017, dalam http: //www.inspire.unisza.edu.my

[19]Ristyana Tri Hastuti \& Ahmad Redi, Pelaksanaan Penyaluran Zakat Oleh Baitul Mal Aceh Sebagai Pendapatan Asli Daerah Dalam Undang-Undang Nomor 11 Tahun 2006 Tentang Pemerintahan Aceh, dalam Jurnal Hukum Adigama.

[20] Edi Suharto, Membangun masyarakat Meberdayakan Rakyat, Bandung, Aditama, 2005, hlm. 66-67.

[21] M. Imam Purwadi, Qardh al-Hasan dalam Perbankan Syariah: Konsep dan Implementasinya Berdasarkan Prinsip Manfaat bagi Pemberdayaan Masyarakat, dalam UNISIA, Vol. XXXIII No. 74 Januari 2011, hlm. 141-153.

[22] Fatwa MUI No 4 Tahun 2003 tentang Penggunaan Dana Zakat untuk Istitsmar (Investasi).

[23] https://tarjih.or.id/memanfaatkan-harta-zakat-untuk-modal-usaha/

[24]Mahmudatus Sa'diyah dan Meuthiya Athifa Arifin, Mudharabah dalam Fiqih danPerbankan Syari'ah, EQUILIBRIUM, Volume 1, No.2, Desember 2013, hlm. 302-323.

[25]Baitul Mal Aceh, Laporan Tahun Baitul Mal Aceh 2017, hlm. 15.

[26]Baitul Mal Aceh, Laporan Tahun Baitul Mal Aceh 2017, hlm. 15.

[27]Baitul Mal Aceh, Laporan Tahun Baitul Mal Aceh 2017, hlm. 15. 